This article was published in Dutch in Nederlands Tijdschrift voor Natuurkunde in conjunction with the symposium on Science Policy organized by the Netherlands' Physical Society on 11 Septemiber 1970 in Amsterdam. J. Volger's summary covers the papers presented by J.H. Bannier, J.H. de Boer and A.G. van Vijfeijken. Papers read by C. le Pair and H.G. van Bueren at the symposium had been published extensively in Nederlands Tijdschrift voor Natuurkunde 36 (12), 3 September 1970.

\section{Background of the Symposium}

A number of reasons prompted The Netherlands' Physical Society to present this subject for public discussion. In the first few years after the war, physics made good headway, but now its growth has been cut back in favour of other sciences. During the last five years the budget of the Foundation for the Fundamental Research of Matter (FOM) has remained static. Physicists are becoming restless about the lack of clarity in science policy and the measure of secrecy that surrounds the making of decisions affecting the growth or restriction in some fields of research. Even the situation in the United States, where a drastic reduction in research budgets led to relatively high unemployment among physicists, is becoming relevant. To throw light on Dutch science policy seemed therefore both desirable and necessary, and the numerous attendance at the meeting clearly indicated the deep concern felt by Dutch physicists.

The contributions to the symposium backed up the interests and supported the point of view of Dutch physicists while urging moderation. It must now be clear to all that the questions discussed are closely linked with the complexities of economic policy. Progress in scientific research is bound to result from a clarification of the position and value of our science in its social context, enabling advisory and other decision-making bodies to stand on firmer ground.

\section{Summaries of Papers}

Examining the relations between science policy and physics J.H. Bannier, a former director of the Organization for Pure Research (ZWO) stated frankly that the government's science budget was a political matter, the reduction in money and manpower being due to competition with other government expenditure. Scientific programmes need thorough assessment, e.g. on the basis of Weinberg's criteria (A.M. Weinberg: Reflections on Big Science. MIT Press, 1967) :

- Is the field ripe for further research?

\title{
Science Policy in the Netherlands
}

\section{J. Volger}

- Is manpower available?

- What is the technological merit (direct benefit)?

- What is the scientific merit (indirect benefit)?

-What is the social significance?

The Netherlands' Advisory Board on Science Policy has tried to effect a more extensive integration of criteria assessing scientific activity with regard to its implications on

- the spiritual and cultural standard of living,

- the social conditions,

- the physical conditions,

- the economic potential, and

- the Dutch position in the international context.

But even these terms of reference will have to be further extended. The Board is of the opinion that the sciences must have some funds at their disposal and, with an assumed growth in the national income of $5 \%$ per annum, has been recommending an increase in the science budget of $15 \%$ for some years. This circumstance is the cause of difficulties, for the range of instruments used in the Organization for Pure Research (ZWO), indicated by The Netherlands' Advisory Board on Science Policy and including the system of differentiated percentage increases, has put physics in a predicament in view of the limiting budgetary fringe conditions. The ZWO would like to see the budget increased at the cost of those of the universities, but the government remains hesitant, since the question of the so-called secondary flow of funds (ZWO, FOM and others) is still being studied in its broader context. One advantage could ensue from these difficulties: the need for the discouragement of mediocrity.

J.H. de Boer, President of FOM discussed science policy within physics, surveying the activities of the FOM. After years of growth and prosperity there is now budgetary stagnation everywhere, i.e. recession, for each item of research the sophistication alone already requires a $5 \%$ increase per year. He considered Weinberg's criteria much more appropriate than those of the Advisory Board on Science Policy. Defining the scientific merit of a programme should be a matter for the whole community of physicists, who would also have to define the priorities. The technological merits are presumably also being considered within the FOM, although a little hesitantly. The assessment of the social merit should not be left solely to politicians. Although the physicists cannot survey and predict all implications, they must nevertheless give thought to and collaborate in the preparation of information and reports.

Technological forecasting was the subject of the paper by A.G. van Vijfeijken (Philips). He outlined a mode of thought that is at present gaining ground in the larger industrial laboratories. On the one hand, the functions which society at large requires to be fulfilled (e.g. communications, energy supply) are defined, on the other, there are the systems and the technical realizations which industry can offer for performing these functions. An enterprise will attempt to supply certain systems if this agrees with its objectives. The significance of technological forecasting can be seen in refining the motivation of research and development programmes. Another result is the more accurate prediction of a market development or of a political policy formulation, and also the closer consideration of the consequences (higher order effects) of an innovation, which necessitates the co-operation of those working in the $\gamma$-fields (fields outside the exact sciences).

\section{Forum Discussion}

Ample opportunities were provided for discussion. A forum was set up consisting of the symposium speakers as well as H.B.G. Casimir, member of the Advisory Board on Science Policy, and A.J. Piekaar, Director General of the Department of Education and Science; C.C. Jonker chaired the discussion. The main points concerning decision making in science policy are summarized below : 
Aerial view of the Institute of Plasma Physics at Jutphaas (south of Utrecht). This institute has been built and is financed by the FOM.

\section{Finance}

One most remarkable and perhaps most annoying factor in the nonindustrial science budget is that, according to A.J. Piekaar, total government expenditure in 1970 amounted to 550 million guilders but that the allocation to various items in the technological and other universities is not centrally known. (In 1969 the physicists received 45 million guilders from the universities and technological universities and 25 million from FOM.) An improvement in this situation should be demanded in political circles. The Academic Advisory Board has clearly insisted on an inter-university research policy. There would also have to be a co-ordinated policy of appointments. The question of what will happen to the secondary source of funds is becoming more and more urgent. With this is linked the problem of how far scientific education and research should be separated in the long term. The government is still considering this, and it is certainly clear that the future of the Veringa law (new law for the organization of universities in the Netherlands), the existing personnel situation in higher education and the prediction that "scientific research must go through the purgatory of democratization" (heard in parliamentary circles) play an important rôle here. The transfer of money from the universities to pure research (ZWO) may result in better co-ordination, but not without danger to higher education.

\section{Assessment and Assessors}

Even if there were agreement on the criteria, the terms of reference of those assessing the elements of the science policy remain unclear. It is becoming more and more difficult to find independent and competent advisers because of increasing specialization and complexity. Almost all specialists are either partly responsible for the present situation, or are concerned with the results of the decision. Opinion is growing that the intrinsic criteria (Weinberg's first two) - with appeal facilities - should be the responsibility of a representative group of able physicists, and the extrinsic criteria (the last three) that of a mixed group of politicians, $\gamma$-specialists and physicists. Would we have to consider setting up a scientific parliament, or would the Academic Advisory

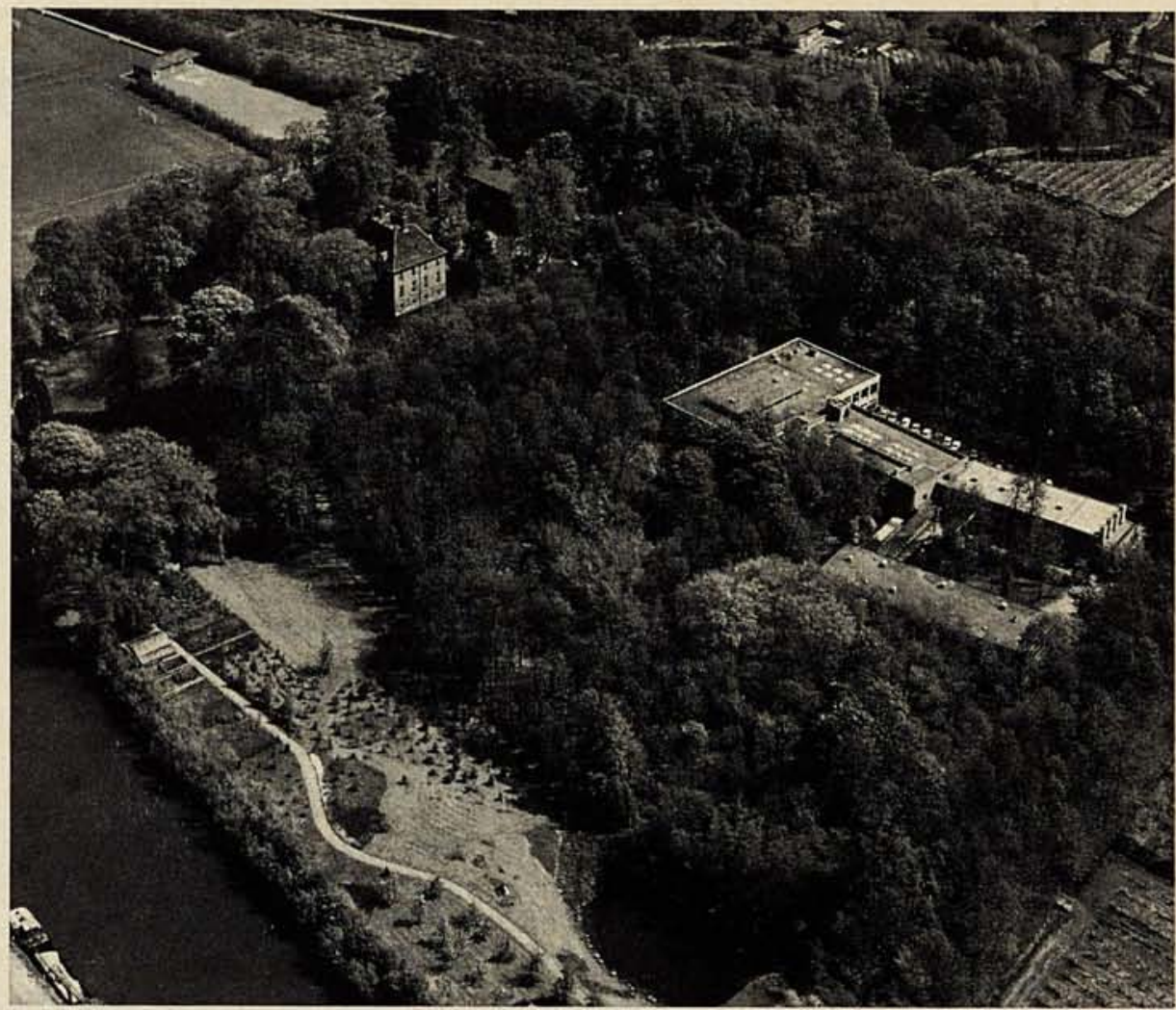

Board, as it is now, be able to function as such in the long run? A more profound study of the question of assessment is considered desirable. There is a need, in this connection, for closer knowledge of the elementary data in the financial and economic field, but one would also like to know how best to practise science. We shall only be able to work marginally if we, in the Netherlands, wish to be active in every field. The development of the $\gamma$-branches could be stimulated by applying technological forecasting.

Industry must not play a disproportionate rôle in Dutch science policy. Instead, the well-being of our people and the world should be the primary consideration.

\section{Co-ordination}

A monolithic policy of subsidies is generally regarded as dangerous and undesirable. There must always be a safety valve, so that good original work can be given another chance. It is important that we first agree on "areas of interest", for which specifications of the desired and necessary research can be laid down afterwards and then examined to decide where it can best be carried out. In reply to questions on this subject ("Are there not too many cyclotrons ?") some forum members said that they believed a little dispersion of effort in physics research not to be too serious. What is important is the periodical critical examination of current research programmes and the possibility of them being wound up. The central question remains whether and how we can keep pace in the international context. Not only are we faced with either chaos or co-ordination, but also with the problems of the mobility of individual research workers and their urge to compete.

\section{Conclusions}

The virtue of the symposium was that the problems outlined above could be expressed in public, a virtue indeed, because the opinions voiced at this meeting of Dutch physicists may influence the high-level deliberations now taking place. Nevertheless, it is strange that none of those present asked The Netherlands' Physical Society whether, as a professional organization, it proposes to publish recommendations on Science Policy. One further could observe that fundamental research is also being conducted by Dutch industry. As to the extent this activity affects the selection of university research programmes, to what degree industrial research could be adapted to the work in the universities, and the increase in the industrial research budget compared to that of the university - none of these subjects were raised. The discussion had more of an informative character than one of sharp opposition between various groups.

Dutch physicists ought to be informed from time to time about the results of consultations, the progress in formulating criteria and new aspects regarding the choice of subjects. Perhaps The Netherlands' Physical Society may soon be able to organize a sequel to this symposium. 